Check for updates

The BMJ

Cite this as: BMJ 2021;375:n2423 http://dx.doi.org/10.1136/bmj.n2423 Published: 04 October 2021

\section{Covid-19: Chikwe Ihekweazu: "It's a rare privilege" to lead new pandemic hub}

\author{
Gareth lacobucci spoke to the head of the World Health Organization's new Hub for Pandemic and \\ Epidemic Intelligence about his ambitions for the venture
}

\section{Gareth lacobucci}

Was the world sufficiently prepared for covid-19? Whatever the answer to that question, WHO's new $\mathrm{Hub}$ for Pandemic and Epidemic Intelligence ${ }^{1}$ wants to ensure that lessons are learnt and acted on. It aims to facilitate greater sharing of better information, so that the global response to future health emergencies is smarter, quicker, and more effective (see box 1).

\section{Box 1: What WHO's new hub aims to provide \\ - Enhanced methods for access to multiple data sources vital to generating signals and insights on disease emergence, evolution, and impact \\ - Development of state of the art tools to process, analyse, and model data for detection, assessment, and response \\ - Provide WHO, UN member states, and partners with these tools to underpin better, faster decisions on how to tackle outbreak signals and events \\ - Connect and catalyse institutions and networks developing disease outbreak solutions for the present and future. \\ Source: WHO}

The hub, based in Berlin and funded with an initial investment of $\$ 100 \mathrm{~m}$ (£74m; €86m) from the German government, will be led by Chikwe Ihekweazu, an epidemiologist, director general of Nigeria's Centre for Disease Control since 2016, and WHO's new assistant director general of health emergency intelligence (see box 2).

Box 2: Chikwe Ihekweazu: Career profile

- Assistant director general of health emergency, World Health Organization, 2021

- Director general of the Nigeria Centre for Disease Control, 2016-2021

- Acting director of the Regional Centre for Disease Control for West Africa until January 2018

- Trained as an infectious disease epidemiologist. Has held senior public health and leadership positions in various national public health institutes, including the South African National Institute for Communicable Diseases, the UK's Health Protection Agency, and Germany's Robert Koch Institute

- Led several short term engagements for WHO, mainly in response to major infectious disease outbreaks around the world including the WHO-China Joint Mission on Coronavirus Disease 2019

\section{Why has the hub been established?}

From my perspective, the lesson that we've learnt from this outbreak and others is that we've got to think a bit more broadly about sources of information, about systems for collecting information, and how to use this most effectively and efficiently to make decisions. Currently there isn't a very efficient way of condensing data from different countries into usable chunks of information that can lead to decisions being made at the global and interconnected level. There's a realisation that all countries need to work together more. And so WHO came up with this concept-a separate team that is looking at data and supporting the building and sharing of systems and data in order to deliver better decisions.

\section{Will it provide a service that doesn't exist elsewhere?}

There have been many approaches to collecting data and making decisions, but they've been developed in a disease specific way. We've got great flu surveillance systems, great tuberculosis surveillance systems, but not necessarily systems that aren't for specific diseases. One of the components of this hub is that it needs to be disease agnostic. If you think about systems that have been built in other sectors that work with uncertainty-weather forecasting systems, the systems around earthquakes-these are much further developed in the use of different data points to improve decision making. What often happens is that decisions taken at the beginning of an event are not as specific as we would like them to be. That's really what WHO is trying to do here-start a pathway of enabling us to really look at different sources of data and information and use it to make decisions.

\section{Will the hub allow nations to be better prepared for future pandemics?}

Absolutely. On reflection, there are a lot of things that happened at the beginning of the outbreak that if we had fully understood, we could have prepared better. For instance, travel patterns, potential for transmission-if we could combine airline data with virulence data and different data sources on a global level, we could potentially have been better equipped to say what was happening and how to respond. You can't build those systems in the middle of a storm. You need the storm to recede a bit. Covid hasn't gone away, but there is some light at the end of the tunnel and now is the time to use those lessons to start building the system for the future. 


\section{Will you be focusing on certain parts of the world?}

It's hard to focus the work that we do geographically with any level of confidence that that's where the next intense activity would be. If, before covid, anyone had predicted that in the next pandemic one of the highest case fatality ratios globally would be the US, people would think that you're out of your mind. It's important for each country to build the capacity for themselves. But because the world is so interconnected, we'll get much more value if each piece is connected with each other. It's not going to be easy by any means. We live in a very polarised world. There's some hesitation about the sharing of data in many parts and in some parts there is a lack of capacity to share. It will not change the world in a few weeks. But at least we will have an intense focus on activity in this area -that we've identified a gap in the global health security architecture and can try to start to fix that.

\section{What impact do you hope it will have on decision making?}

Ultimately, public health decisions are often political decisions so we can't necessarily ensure that the right decisions are made. There are many decisions being made right now that we have enough data on to make them different. If you look at vaccine distribution, it's not about whether you have good data or don't, it's about the political courage to make the right decisions. So we aren't assuming that just by providing better data that better decisions will be made. But we can influence that and make sure our leaders have the opportunity to make better decisions.

\section{How will the new hub disseminate information?}

I suspect some will be shared publicly, some privately. But the first thing is to build confidence with our partners to enable greater access to existing data systems. We want them to be as open as possible. We don't envisage the hub will have WHO staff working in it. It's been designed to attract the brightest minds to spend periods of time with the hub informing specific questions that need that need answering, to support our collective thinking and action, and then to go back to in their institution while maintaining a relationship as a source of expertise in a specific virus, mode of transportation, modelling, or whatever the expertise is.

\section{How many WHO staff will work in the hub?}

We are looking to build up to 100 people, but there are ideas for campuses of the hub in different parts of the world. But everything we're going to do will be fully integrated and working to support the leadership of WHO within the WHO health emergencies programme.

\section{Why did you decide to take this role on?}

It's a great opportunity to take a lot of the lessons from this pandemic response to tackle what we all recognise is one of the biggest challenges of our lifetime. It's a rare privilege to be part of a potential solution to such a big problem that none of us could even imagine solving on our own. We really need collective intelligence. My role is to find a way of attracting those people together, to work in a way where our collective best interest outweighs any personal interest. I'm excited about the opportunity. There's often a lot of scepticism about our ability to work together. I think we all have a responsibility to provide an alternative narrative.
This article is made freely available for use in accordance with BMJ's website terms and conditions for the duration of the covid-19 pandemic or until otherwise determined by BMJ. You may use, download and print the article for any lawful, non-commercial purpose (including text and data mining) provided that all copyright notices and trade marks are retained. 